\title{
Attitudes and knowledge of healthcare providers toward pain management in a level 2 hospital in Burkina Faso
}

\author{
Martin Lankoandé, MD (1) - Georges Mion, PhD • Kellan Bertille Ki, MD • \\ Papougnezambo Bonkoungou, PhD • T. H. W. Cheik Bougouma, MD • R. A. Flavien Kaboré, PhD • \\ Nazinigouba Ouédraogo, PhD
}

Received: 1 August 2019/Revised: 12 November 2019/Accepted: 13 November 2019/Published online: 2 December 2019

(C) Canadian Anesthesiologists' Society 2019

\section{To the Editor,}

Acute or chronic pain is a socially threatening experience. ${ }^{1}$ The majority of the world's population (85\%) suffers from physical pain with family, occupational, social, and financial repercussions. Pain remains undertreated, and the reasons for this "oligoanalgesia" are inadequate assessment, insufficient knowledge, and negative attitudes. ${ }^{2}$ Barriers to pain management are grouped into those related to patients, drug availability, health systems, and health professionals' knowledge and attitudes. In Burkina Faso, there is no policy or training program related to pain, and opioid legislation remains restrictive. At the regional hospital of Koudougou, many patients continue to complain about

Electronic supplementary material The online version of this article (https://doi.org/10.1007/s12630-019-01542-1) contains supplementary material, which is available to authorized users.

M. Lankoandé, MD ( $₫)$

Regional Hospital of Koudougou, Koudougou, Burkina Faso

e-mail: m.hamtaani@gmail.com

G. Mion, PhD

Cochin Hospital, Paris, France

\section{K. B. Ki, MD}

Teaching paediatric hospital Charles De Gaulle, Ouagadougou, Burkina Faso

P. Bonkoungou, $\mathrm{PhD}$

Teaching Hospital Yalagado, Ouadraogo, Ouagadougou,

Burkina Faso

T. H. W. C. Bougouma, MD - R. A. F. Kaboré, PhD .

N. Ouédraogo, $\mathrm{PhD}$

Teaching Hospital Tingandogo, Ouagadougou, Burkina Faso pain when receiving emergency treatment and on the postoperative ward.

After approval from the Koudougou regional hospital's review board (approval no. 01074/2017), we carried out a cross-sectional survey to assess the knowledge and attitudes of 196 healthcare providers (HCP) toward pain in our level 2 hospital. The level of knowledge and attitudes among HCP was assessed using the Pain Knowledge and Attitudes (PAK) questionnaire. ${ }^{3}$ The PAK is a ten-item self-administered questionnaire (eAppendix, available as Electronic Supplementary Material) with each item scored on a Likert scale. A correct answer to each item was comprised of either a "disagree" or "absolutely disagree" response (either of which was allocated one point) with the three other responses considered as incorrect (with zero points allocated). A good PAK performance was defined as at least $80 \%$ correct responses. StatEL for Excel software (www.adscience.fr) was used for statistical analysis.

The response rate was 64\% (124/196). The mean (standard deviation [SD]) age was 41 (7) yr. Most HCP $(55 \%, 68 / 124)$ scored below $80 \%$ and the average proportion of correct answers was $40 \%$. Physicians and pharmacists obtained a higher mean (SD) overall score of correct responses than nurses [5.6 (1.4) vs 3.9 (1.8), respectively; $P=0.006$ ], and nurse anesthetists obtained a higher mean (SD) overall score of correct responses than non-anesthetists [5.3 (1.4) vs 3.8 (1.9), respectively; $P<$ $0.001]$. There were no significant differences regarding sex or length of practice (Table). Past training in pain management did not significantly alter the score between HCPs (Table).

In this study, compared with the recommended threshold PAK score of $70-80 \%,{ }^{4}$ the average score $(40 \%)$ of correct responses reveals that $\mathrm{HCP}$ are not optimally qualified to 
Table Comparison of Pain Knowledge and Attitudes scores of healthcare providers $(n=124)$

\begin{tabular}{|c|c|c|c|c|}
\hline Characteristics & Group of HCP & $n$ & $\begin{array}{l}\text { Average score } \\
\text { mean (SD) }\end{array}$ & $P$ value \\
\hline \multirow[t]{2}{*}{ Sex } & Male & 74 & $4.1(1.8)$ & \multirow[t]{2}{*}{0.61} \\
\hline & Female & 50 & $3.9(2.0)$ & \\
\hline \multirow[t]{2}{*}{ Profession } & Doctor/pharmacist & 13 & $5.6(1.3)$ & \multirow[t]{2}{*}{$<0.01$} \\
\hline & Nurse & 111 & $3.9(1.9)$ & \\
\hline \multirow[t]{2}{*}{ Specialty } & Anesthetist & 21 & $5.3(3.0)$ & \multirow[t]{2}{*}{$<0.001$} \\
\hline & Non-anesthetist & 103 & $3.8(2.1)$ & \\
\hline \multirow[t]{2}{*}{ Years of experience } & $\leq 5$ years & 42 & $4.4(2.0)$ & \multirow[t]{2}{*}{0.21} \\
\hline & $>5$ years & 82 & $3.9(1.8)$ & \\
\hline \multirow[t]{2}{*}{ Trained in pain management } & Yes & 12 & $4.3(2.1)$ & \multirow[t]{2}{*}{0.86} \\
\hline & No & 112 & $4.0(1.1)$ & \\
\hline
\end{tabular}

$\mathrm{HCP}=$ healthcare provider; $\mathrm{SD}=$ standard deviation

The Pain Knowledge and Attitudes (PAK) questionnaire has 10 items. Each item had a correct response of "disagree" or "absolutely disagree" that scored 1 point. The other responses were considered incorrect and scored 0 points. The PAKs core range was from 0 to 10 points

manage pain. A prior study ${ }^{5}$ noted that nurses tend to assess pain more liberally and offer opioids more readily than doctors, but this trend does not seem to be based on facts. Several studies have confirmed that doctors score higher than nurses. ${ }^{3}$ Among physicians, specialists have better knowledge than others. As in other studies, anesthetists had higher scores than non-anesthetists. ${ }^{3}$

Training is the cornerstone of pain management. ${ }^{2}$ Our study reveals a non-significant improvement in the mean (SD) score of correct responses between staff trained for pain management compared with untrained staff [4.3 (2.1) vs 4.0 (1.0), respectively; $P=0.12$ ]. These training sessions were irregular postgraduate courses where the content was limited to basic pharmacology, and they were generally organized by industry and not official training institutions. In this study, the trained staff were mainly physicians and it was post-university training. Only $10 \%$ had good performance for pain management.

Overall, we observed poor knowledge and incorrect attitudes toward pain management in this regional hospital in Burkina Faso. Poor performance was more pronounced in nurses, untrained health personnel, and non-anesthetists. In Burkina Faso, we need to implement guidelines and better policies to promote correct pain management teaching.
Conflicts of interest None.

Funding statement None.

Editorial responsibility This submission was handled by Dr. Hilary P. Grocott, Editor-in-Chief, Canadian Journal of Anesthesia.

\section{References}

1. Karos K, Williams AC, Meulders A, Vlaeyen JW. Pain as a threat to the social self: a motivational account. Pain 2018; 159: 1690-5.

2. Goucke CR, Chaudakshetrin P. Pain: a neglected problem in the low-resource setting. Anesth Analg 2018; 126: 1283-6.

3. Zanolin ME, Visentin M, Trentin L, Saiani L, Brugnolli A, Grassi $M$. A Questionnaire to evaluate the knowledge and attitudes of health care providers on pain. J Pain Symptom Manage 2007; 33: 727-36.

4. McCaffery M, Robinson ES. Your patient is in pain-here's how you respond. Nursing 2002; 32: 36-45.

5. Kumar KH, Elavarasi P. Definition of pain and classification of pain disorders. Journal of Advanced Clinical \& Research Insights 2016; 3: 87-90.

Publisher's Note Springer Nature remains neutral with regard to jurisdictional claims in published maps and institutional affiliations. 